\title{
High-speed visualization of metal oxide precursor in thermal plasma flow during nanoparticle formation
}

\author{
Manabu TANAKA*, Yuki SAITO*, Yushi NAWATA* and Takayuki WATANABE* \\ *Department of Chemical Engineering, Kyushu University \\ 744 Motooka, Nishi-ku, Fukuoka 819-0395, Japan \\ E-mail: watanabe@chem-eng.kyushu-u.ac.jp
}

Received: 2 April 2019; Revised: 22 July 2019; Accepted: 2 October 2019

\begin{abstract}
The objective of the present study is to understand formation mechanism of metal oxide nanoparticles in thermal plasma. High-speed camera technique with appropriate band-pass filters was applied to visualize the precursors of the metal oxide nanoparticles. A multiphase AC arc was generated under atmospheric pressure of air with aluminum raw powder injection to synthesize aluminum oxide nanoparticles. Optical emission spectroscopy of the multiphase $\mathrm{AC}$ arc was performed to select the transmission wavelengths as $514.5 \mathrm{~nm}$ and $670.0 \mathrm{~nm}$ for emissions from aluminum vapor and aluminum monoxide, respectively. Dynamic behavior of aluminum vapor and aluminum oxide was successfully visualized by the high-speed camera observation with these band-pass filters. Relative intensities of aluminum emission to argon emission as well as aluminum oxide emission to argon emission were calculated to estimate relative number densities of aluminum vapor and aluminum oxide. Results clearly revealed that aluminum vapor mainly existed at the higher temperature region than $4,000 \mathrm{~K}$, while aluminum oxide became dominant at the lower temperature region. These obtained results experimentally elucidated that aluminum oxide nucleates at first, and then aluminum oxide condenses onto the nuclei.
\end{abstract}

Keywords : Thermal plasma, Multi-phase alternating current arc, High-speed imaging, Aluminum oxide nanoparticles, Formation mechanism

\section{Introduction}

Recent advances in nanotechnology have enabled researchers to control the morphology, phase composition by a wide variety of synthesis techniques such as liquid phase method. However, one common disadvantages of these techniques is their low production capability, either due to their scaling limitation of the equipment, their long operation time and/or large amount of steps required. Instead of these methods, thermal plasma method is one of the most promising method to synthesize many kind of nanomaterials such as pure metals, alloys, intermetallic compounds, carbides, nitrides, and oxides at high-production rate in the order of kilograms per hour (Kodama et al., 2014; Homma et al., 2014). This is because of its unique advantages such as high temperature, high enthalpy to enhance reaction kinetics, rapid quenching capability to produce chemical non equilibrium materials, and selectivity of atmosphere in accordance with required chemical reactions. These advantages have brought advances in plasma chemistry and plasma processing (Heberlein and Murphy, 2008; Shigeta and Murphy, 2011).

A multiphase $\mathrm{AC}$ arc is one of the most attractive thermal plasma sources due to its advantages; higher energy efficiency, larger plasma volume, and lower gas velocity compared with the conventional thermal plasma sources. Therefore, the multiphase $\mathrm{AC}$ arc has been applied to an innovative material processing such as in-flight glass melting technology (Watanabe et al., 2010) and nanomaterial fabrication processes. Previous researches on fundamental phenomena in the multiphase AC arc revealed its unique spatial and temporal characteristics (Tanaka et al., 2017: Okuma et al., 2018), which could have strong influence on the nanoparticle formation of metal oxide and their properties.

Formation mechanism of nanoparticles composed of metals or intermetallic compounds in thermal plasma have been clarified experimentally and numerically. Nanoparticle formation mechanisms of metal silicide (Watanabe et al., 2001; Shigeta and Watanabe, 2005, 2007a, 2016) and metal boride (Cheng et al., 2012; Shigeta and Watanabe, 2007b) have 
been successfully understood. In contrast, formation mechanism of metal oxide nanoparticles remains to be explored due to its complexity owing to oxidation during rapid quenching process. To overcome this difficulty, high-speed visualization of precursors in thermal plasma flow have recently been focused. High-speed camera visualization combined with an imaging spectrometer was applied to investigate the formation mechanism of titanium dioxide nanoparticles by induction thermal plasma (Kodama et al., 2016). In the present study, high-speed camera system with appropriate band-pass filters has been established to investigate fundamental phenomena during metal oxide nanoparticle synthesis process by thermal plasma. Then, the purpose of the present study is to understand the formation mechanism of oxide nanoparticles in the multiphase AC arc on the basis of the high-speed visualization.

\section{Experiments}

\subsection{Plasma generation}

A schematic illustration of the multiphase AC arc is shown in Fig. 1. It consisted of 6 electrodes, an arc chamber, and AC power supply at $60 \mathrm{~Hz}$. These electrodes with a diameter of $6 \mathrm{~mm}$ were made of tungsten (98wt\%) and metal oxide $(2 \mathrm{wt} \%)$. Lanthanum oxide was doped into $\mathrm{W}$ to reduce the effective work function to generate a stable thermionic emission. Argon gas was injected around the electrode to prevent them from oxidation, which results in severe erosion. City-water was used to cool the electrodes at a water flow rate for each electrode. The electrodes were symmetrically arranged at angles of $60 \mathrm{deg}$. The 6-phase AC arc was generated under atmospheric pressure at a total gas flow rate of about $300 \mathrm{~L} / \mathrm{min}$. Table 1 shows the list of the gas composition. $\mathrm{O}_{2}$ gas was injected from the upper plasma torches at the flow rates of 0 to $36 \mathrm{~L} / \mathrm{min}$ to control the $\mathrm{O}_{2}$ concentration in the plasma chamber from $18 \%$ to $29 \%$. Flow rate of Ar shield gas was $6 \mathrm{~L} / \mathrm{min}$ for each electrode. Note that all of the gases were not fed into the discharge region because the electrode gap distance of $60 \mathrm{~mm}$ is smaller than the inner diameter of the arc chamber of $200 \mathrm{~mm}$.

Typical operating conditions are as follows; pressure: $101 \mathrm{kPa}$, arc current per each electrode: $80 \mathrm{~A}$, input power: 12 $\mathrm{kW}$ for lower $\mathrm{O}_{2}$ concentration and $15 \mathrm{~kW}$ for higher case, the diameter among the electrode region: $60 \mathrm{~mm}$, the number of the phases: 6 phase. More details about the equipment of the multiphase AC arc including power supply are available in our previous reports (Watanabe et al., 2010).

\subsection{Raw materials}

Micron-scaled powders were injected into the multiphase AC arc from the top of the chamber by powder feeder. Powders of $\mathrm{Ti}, \mathrm{Al}, \mathrm{Cu}, \mathrm{Cr}, \mathrm{Fe}, \mathrm{Ni}, \mathrm{Nb}$, and $\mathrm{MgO}$ were utilized as raw materials of each metal oxide. Each raw material was injected into thermal plasma region by Ar carrier gas of $5 \mathrm{~L} / \mathrm{min}$ at a powder feed rate of $2 \mathrm{~g} / \mathrm{min}$. Raw materials were completely evaporated in thermal plasma region. Super-saturated metal vapor or metal oxide during quenching process leads to its homogeneous nucleation. Then, remained metal and/or metal oxide is condensed onto the nucleus, forming metal oxide nanoparticles. This work focuses on the oxidation process during metal oxide nanoparticle formation.

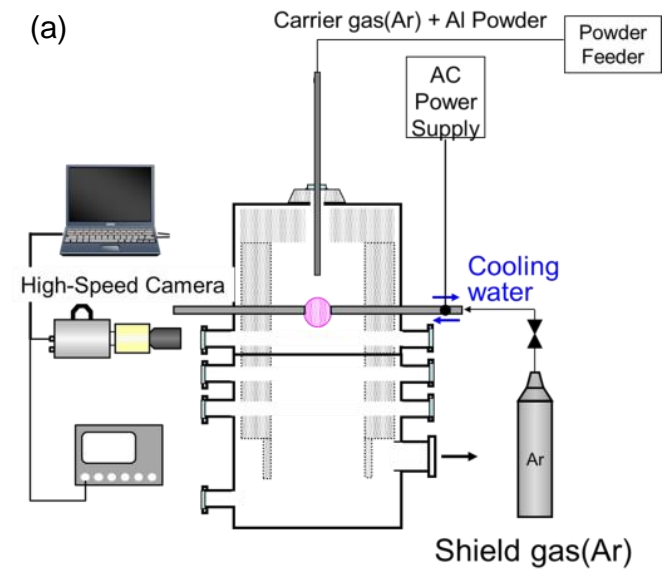

(b)

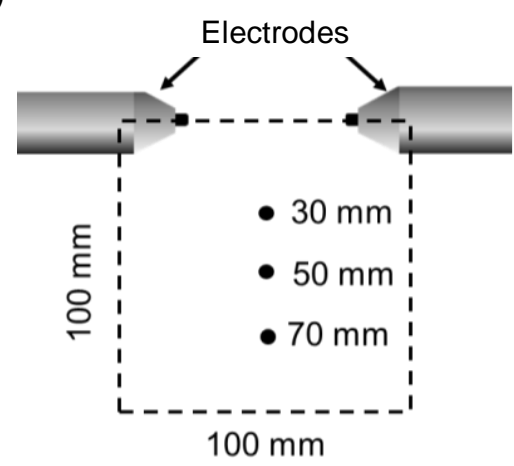

Fig. 1 (a) Cross-sectional side view of multiphase AC arc reactor and (b) enlarged image of observation region by a high-speed camera system. 
Table 1 Gas flow conditions and compositions for lower and higher $\mathrm{O}_{2}$ cases.

\begin{tabular}{|c|c|c|c|c|c|}
\hline \multirow{2}{*}{ Element } & \multirow{2}{*}{ Gas } & \multicolumn{2}{|c|}{ Lower $\mathrm{O}_{2}$ Concentration } & \multicolumn{2}{|c|}{ Higher $\mathrm{O}_{2}$ Concentration } \\
\hline & & Flow rate $[\mathrm{slpm}]$ & Concentration[vol\%] & Flow rate [slpm] & Concentration[vol \\
\hline $\mathrm{Ar}$ & Sheild gas & 36 & \multirow{2}{*}{14} & 36 & \multirow{2}{*}{12} \\
\hline $\mathrm{Ar}$ & Carrier gas & 5 & & 0 & \\
\hline $\mathrm{O}_{2}$ & Carrier gas & 0 & \multirow{3}{*}{18} & 5 & \multirow{3}{*}{29} \\
\hline $\mathrm{O}_{2}$ & Additional gas & 0 & & 36 & \\
\hline $\mathrm{O}_{2}$ & Air (259 lpm) as plasma gas (20.95\% in Air) & 54 & & 47 & \\
\hline $\mathrm{N}_{2}$ & Air (259 lpm) as plasma gas ( $78.08 \%$ in Air) & 202 & 67 & 174 & 58 \\
\hline Others & Air (259 lpm) as plasma gas ( $0.97 \%$ in Air) & 3 & 1 & 2 & 1 \\
\hline Total & & 300 & 100 & 300 & 100 \\
\hline
\end{tabular}

\subsection{Measurement system}

Visualization system was composed of a high-speed camera (FASTCAM SA-5, Photron Ltd., Japan) and an optical system (MSI-2, Photron Ltd., Japan) including the band-pass filters, as shown in Fig. 2. Conventionally, to observe the particular emission from thermal plasmas was difficult because strong radiations based on different emission mechanisms exist around thermal plasma region. Therefore, appropriate band-pass filters were utilized to observe particular species in thermal plasma to overcome the difficulties. This system enables to observe two different images of the particular species at two different wavelengths simultaneously. Emissions from metal, metal oxide, and Ar as plasma gas were focused in the present work. Typical frame rate and shutter speed were 5,000fps and $0.2 \mathrm{~ms}$, respectively.

One of the most important parts of visualization is to select appropriate emissions. Spectroscopic measurements (iHR 550, Horiba Jobin Yvon, Japan) were conducted to select the appropriate transmission wavelengths of the band-pass filters for the emissions from atomic argon. In addition, temperature measurement was also conducted on the basis of Boltzmann plot method with line emissions from metal vapor in the case of aluminum injection. The selected line emissions from atomic aluminum were listed as shown in Table 2. These two emissions were selected because (i) they have a wider energy gap between their excitation energies and (ii) these lines are well isolated from other emissions including aluminum oxide. Excitation temperature of aluminum vapor was measured at different spots with 30, 50, and $70 \mathrm{~mm}$ from the electrode, as shown in Fig. 1.

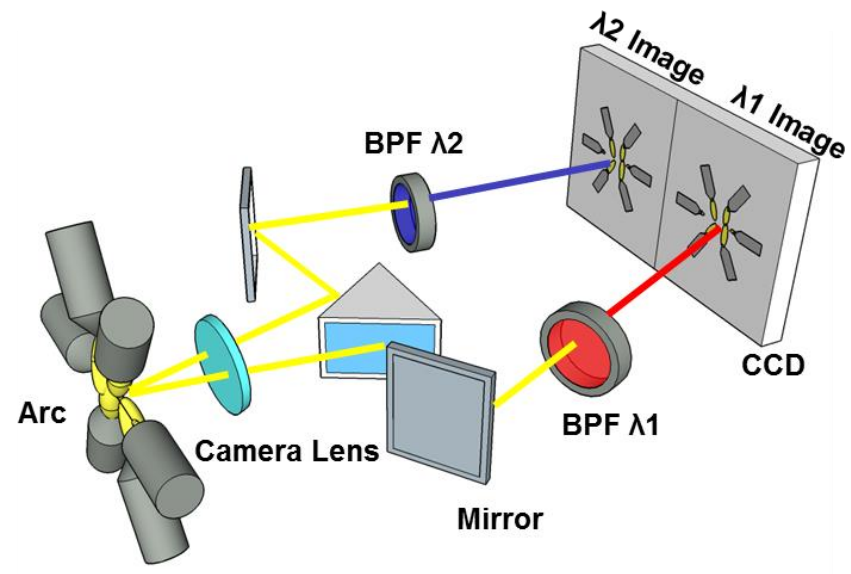

Fig. 2 Conceptual illustration of measurement system of high-speed video camera with appropriate

Table 2 Spectrum table of Al I for Boltzmann plot method in the present work.

\begin{tabular}{c|ccc|}
\hline Wavelength $[\mathrm{nm}]$ & $\begin{array}{c}\text { Excitation } \\
\text { energy }[\mathrm{eV}]\end{array}$ & $\begin{array}{c}\text { Transition } \\
\text { probability }\left[\mathrm{s}^{-1}\right]\end{array}$ & Statistical weight $[-]$ \\
\hline 555.70 & 5.373213 & $2.30 \mathrm{E}+05$ & 4 \\
\hline 669.60 & 4.993821 & $1.00 \mathrm{E}+06$ & 4 \\
\hline
\end{tabular}




\section{Results and Discussion}

\subsection{Optical emission spectroscopy}

Suitable precursor for high-speed visualization was selected on the basis of following criteria. First criterion is thermodynamic stability of metal oxide in gas phase. Second criterion is the intensity of molecular spectrum in the visible wavelength range. Figure 3 shows the Gibbs free energy difference for oxidation of metal considered metal. Results indicated that stable oxide in gas phase exist in the cases of $\mathrm{Nb}, \mathrm{Ti}$, and $\mathrm{Al}$. Stable metal oxide in gas phase is suitable for visualization of metal oxide during nanoparticle synthesis process.

Figure 4 presented the emission spectra from the multiphase $\mathrm{AC}$ arc with different raw materials, (a) Ti, (b) Al, (c) $\mathrm{Cu}$, and (d) Ni. Molecular spectra from $\mathrm{TiO}, \mathrm{AlO}$, and $\mathrm{CuO}$ were clearly observed while that from $\mathrm{NiO}$ was not observed. The relationship between the emission intensity from metal oxide molecule and the Gibbs free energy at 4,500 $\mathrm{K}$ is summarized in Fig. 5. Lower Gibbs free energy difference leads to stronger emission intensity from metal oxide except $\mathrm{Nb}$. The weakest emission intensity from $\mathrm{NbO}$ would be attributed to further oxidation from $\mathrm{NbO}$ to $\mathrm{NbO}_{2}$. As a conclusion, the stable metal oxide with sufficiently strong molecular emission such as $\mathrm{Al}$ and $\mathrm{Ti}$ is suitable for visualization of oxide nanoparticle formation process and $\mathrm{Al}$ is selected in the present work.

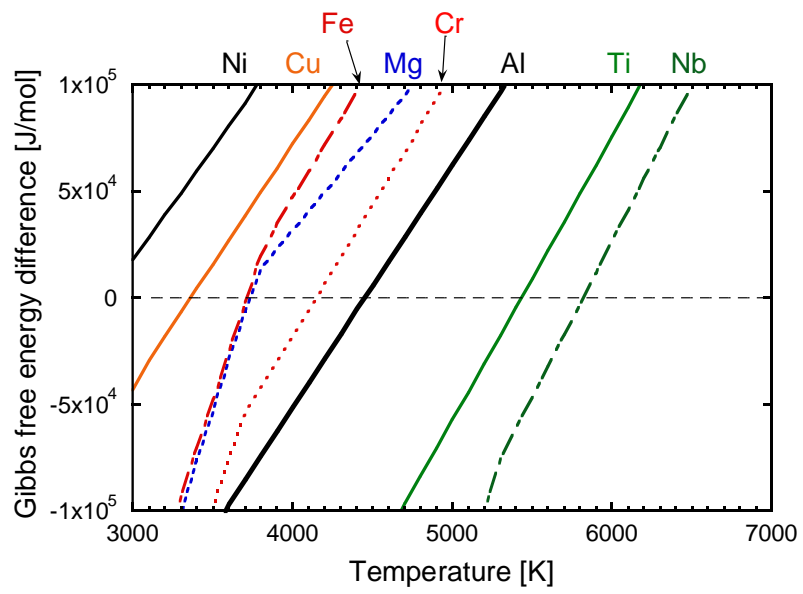

Fig. 3 Relationship between Gibbs free energy difference and temperature for considered metal oxidation to monoxide. $(\mathrm{M}+\mathrm{O}=\mathrm{MO}, \mathrm{M}=\mathrm{Ni}, \mathrm{Cu}, \mathrm{Fe}, \mathrm{Mg}, \mathrm{Cr}, \mathrm{Al}, \mathrm{Ti}$, and $\mathrm{Nb})$.
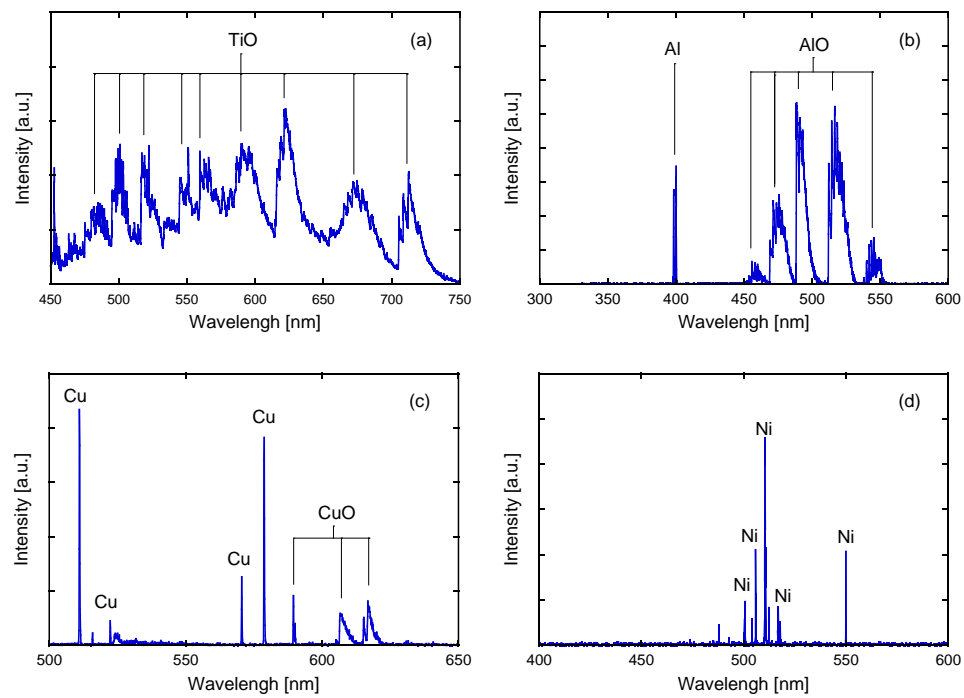

Fig. 4 Representative emission spectra of the multiphase $\mathrm{AC}$ arc under atmospheric pressure during raw powder injection of (a) $\mathrm{Ti}$, (b) $\mathrm{Al}$, (c) $\mathrm{Cu}$, and (d) $\mathrm{Ni}$. 
Emission spectra of the multiphase $\mathrm{AC}$ arc with $\mathrm{Al}$ powder injection at different measurement positions were presented in Fig. 6. Strong emission from $\mathrm{Al}$ atom and $\mathrm{AlO}$ molecule were clearly shown at $10 \mathrm{~mm}$ from the electrode as highest position in the present work. The intensities from $\mathrm{Al}$ atom were decreased with increasing the distance from the electrode. On the other hand, the intensities from AlO relatively increased with increasing the distance. These opposite trends clearly indicate the oxidation of $\mathrm{Al}$ into $\mathrm{AlO}$ occurs with decreasing the temperature. The emission spectra obtained at $30 \mathrm{~mm}$ from the electrode are presented in Fig. 7. The transmission wavelength for AlO was selected as $514.5 \pm 0.5$ $\mathrm{nm}$, while that for $\mathrm{Al}$ was selected as $670.0 \pm 0.5 \mathrm{~nm}$.

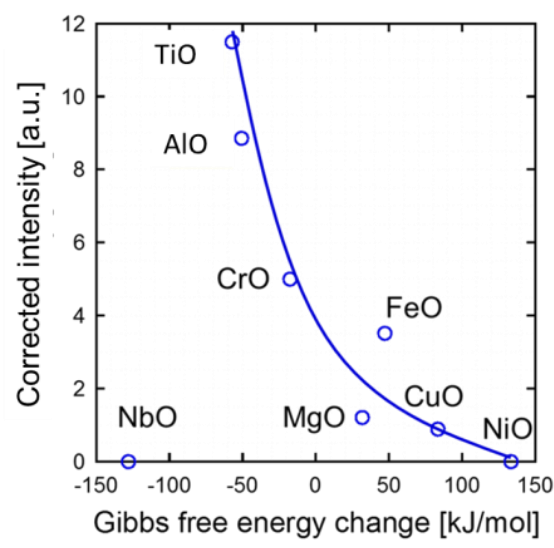

Fig. 5 Relationship between Gibbs free energy change and emission intensity from metal oxide. Measurement position was $30 \mathrm{~mm}$ from the electrode.
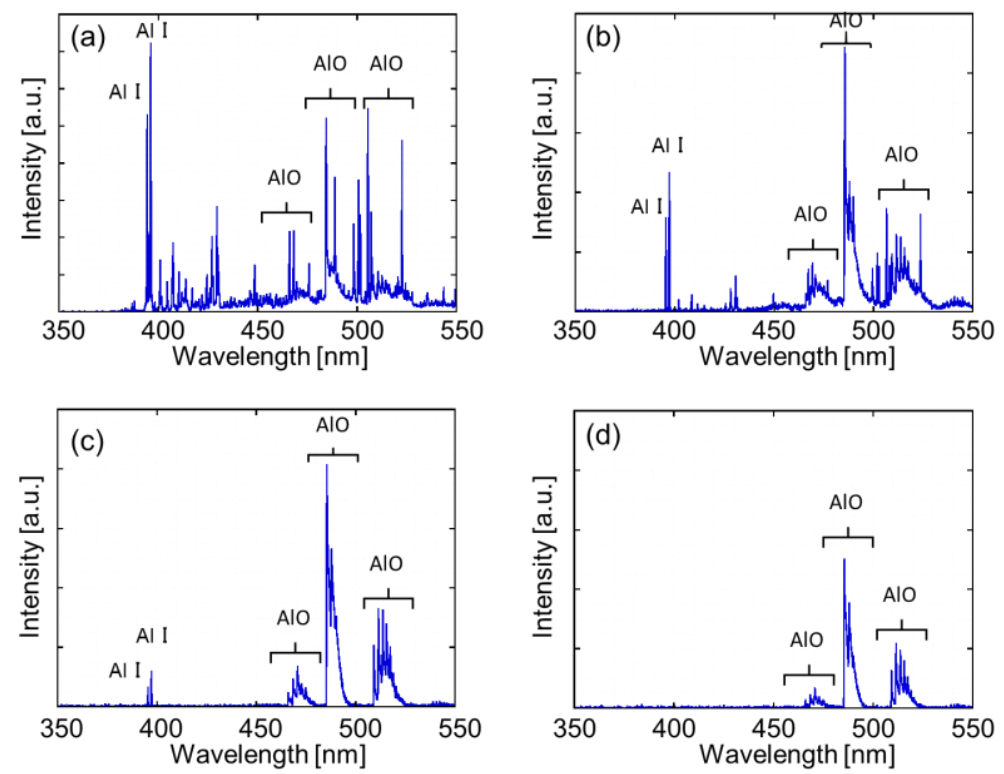

Fig. 6 Representative emission spectra of the multiphase AC arc under atmospheric pressure during $\mathrm{Al}$ powder injection at different positions of (a) $10 \mathrm{~mm}$, (b) $30 \mathrm{~mm}$, (c) $50 \mathrm{~mm}$, and (d) $70 \mathrm{~mm}$ from the electrode.

\subsection{High-speed camera visualization}

Dynamic behavior of $\mathrm{Al}$ and $\mathrm{AlO}$ in the multiphase $\mathrm{AC}$ arc are shown in Fig. 8. Strong emission from AlO vapor was successfully visualized at a wide area in an observation region where the distance from electrode was 0 to $100 \mathrm{~mm}$. On the other hand, strong emission from Al vapor was only observed at the upstream region where the distance from electrode was 0-30 $\mathrm{mm}$. This result is reasonable because the oxidation of Al vapor starts at lower temperature region. Quantitative 

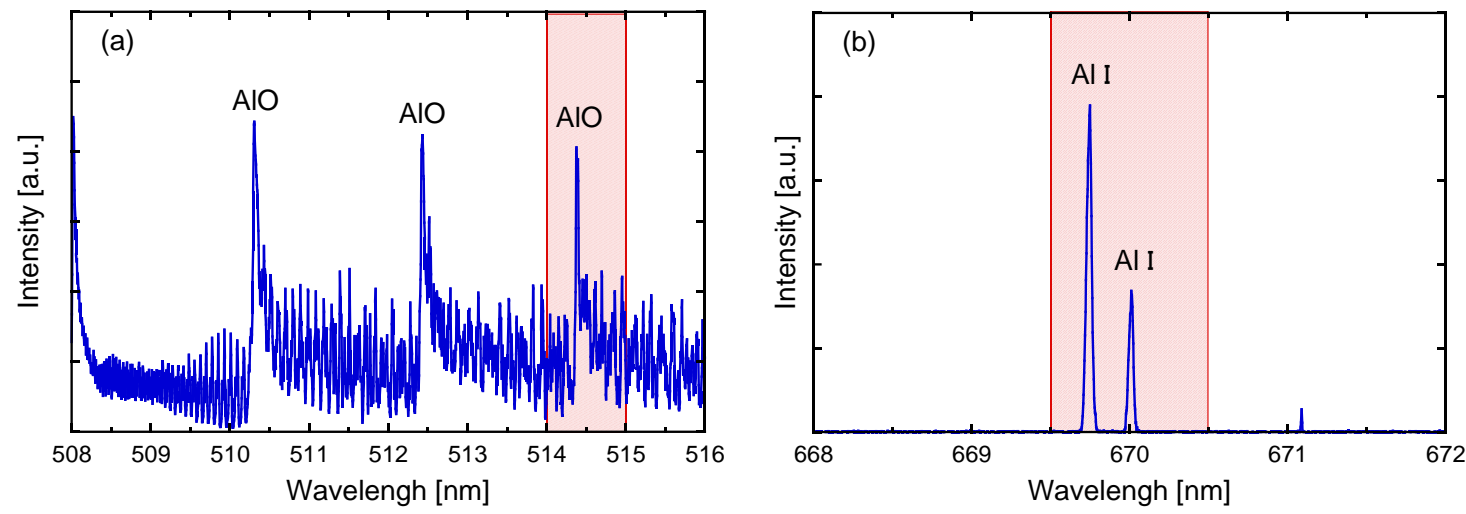

Fig. 7 Representative emission spectra of the multiphase AC arc under atmospheric pressure. Center wavelength was (a) $512.0 \mathrm{~nm}$ and (b) that was $670.0 \mathrm{~nm}$.

discussion about the temperature history based on the OES result will be given at the following paragraphs.

Relative distributions of number density $N$ of vapors are estimated on the basis of the relative intensity distributions. Line emission intensity can be expressed by

$$
\varepsilon_{21}=\frac{\mathrm{hc}_{0}}{4 \pi \lambda_{21}} \frac{g_{2}}{Z(T)} A_{21} N \exp \left(-\frac{E_{2}}{\mathrm{k}_{\mathrm{B}} T}\right)
$$

where $\varepsilon$ is the emission coefficient, $\mathrm{h}$ is Planck's constant, $\mathrm{c}_{0}$ is the light speed, $\lambda$ is the wavelength, $g$ is the statistical weight, $z(T)$ is the partition function, $T$ is the excitation temperature of the considered species, and $\mathrm{k}_{\mathrm{B}}$ is the Boltzmann constant. Subscripts 1 and 2 denote the upper state and lower state, respectively. According to Eq. (1), the emission intensity is a function of the number density and the excitation temperature of the considered species. To reduce the temperature dependence of the emission intensity, the relative intensity of the considered species was estimated with the assumption that the excitation temperatures of each heavy particle were the same.

Distributions of the relative intensities of $\mathrm{Al}$ and $\mathrm{AlO}$ emissions to atomic Ar emission are shown in Fig. 9. Highest relative intensity of $\mathrm{Al} / \mathrm{Ar}$ was observed at $30 \mathrm{~mm}$ from the electrodes. On the other hand, highest relative intensity was found at $60-70 \mathrm{~mm}$ from the electrodes. Temperature measurements were carried out to understand the reason for this result. Then, time-averaged relative intensities distributions were estimated to compare vapor distribution and the obtained temperature distribution. Time-averaged relative intensities of $\mathrm{Al} / \mathrm{Ar}$ and $\mathrm{AlO} / \mathrm{Ar}$ were presented in Fig. 10. Results clearly shows that Al mainly exists at the upstream region while $\mathrm{AlO}$ exists at the downstream region.

The effect of oxygen concentration on the Al oxidation in the thermal plasma is discussed. Figure 11 shows the axial distribution of the relative intensity of $\mathrm{Al} / \mathrm{Ar}$ and $\mathrm{AlO} / \mathrm{Ar}$ with indicating the axial temperature profiles for different oxygen concentrations of $18 \%$ and $29 \%$. In the case of $18 \%$ of oxygen concentration, Al vapor is dominant at higher temperature region than $5,000 \mathrm{~K}$, and $\mathrm{AlO}$ becomes dominant at lower temperature as shown in Fig. 11(a). Relative intensity of $\mathrm{AlO}$ becomes maximum value at 3,500 K, and decreases with temperature decreases. Peak positions of the time-averaged relative intensity were shifted to upstream region with higher temperature when the oxygen concentration was increased. Equilibrium compositions of Al-O-N system with different oxygen concentrations are compared to discuss on the above results. Figure 12 shows the $\mathrm{Al}$ and $\mathrm{AlO}$ mole fraction from equilibrium compositions of Al-O-N system with oxygen concentration of $18 \%$ and $29 \%$. Cross temperature of $\mathrm{Al}$ and $\mathrm{AlO}$ is $3,700 \mathrm{~K}$ when oxygen concentration is $18 \%$, while that was $4,300 \mathrm{~K}$ at $29 \%$ of oxygen concentration. Therefore, different oxygen concentration led to different spatial distributions, while one common phenomenon was that the Al oxidation occurred in vapor phase at different oxygen concentrations. These results experimentally elucidated that the Al vapor is oxidized before nucleation occurred in the downstream region of thermal plasma. Then, AlO nucleation occurred and remained AlO molecule condensed onto the nuclei, forming $\mathrm{Al}_{2} \mathrm{O}_{3}$ nanoparticles. 


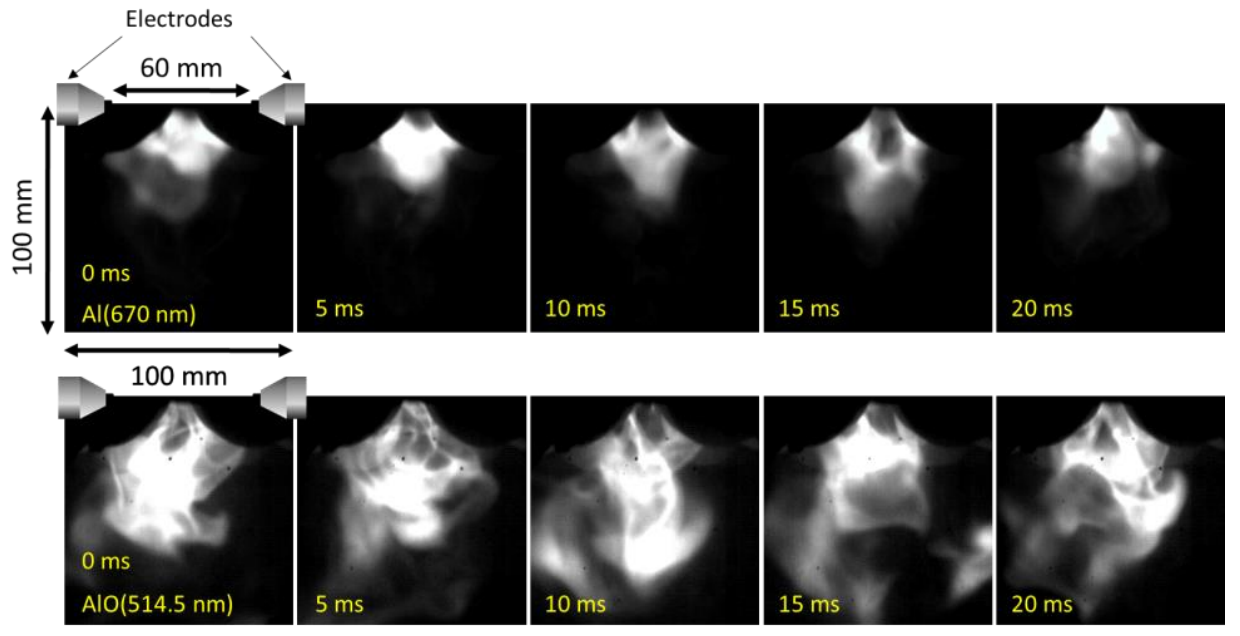

Fig. 8 High-speed snapshots of the multiphase AC arc through the band-pass filters with transmission wavelength of $670.0 \mathrm{~nm}$ for $\mathrm{Al}$ vapor and $514.5 \mathrm{~nm}$ for $\mathrm{AlO}$.

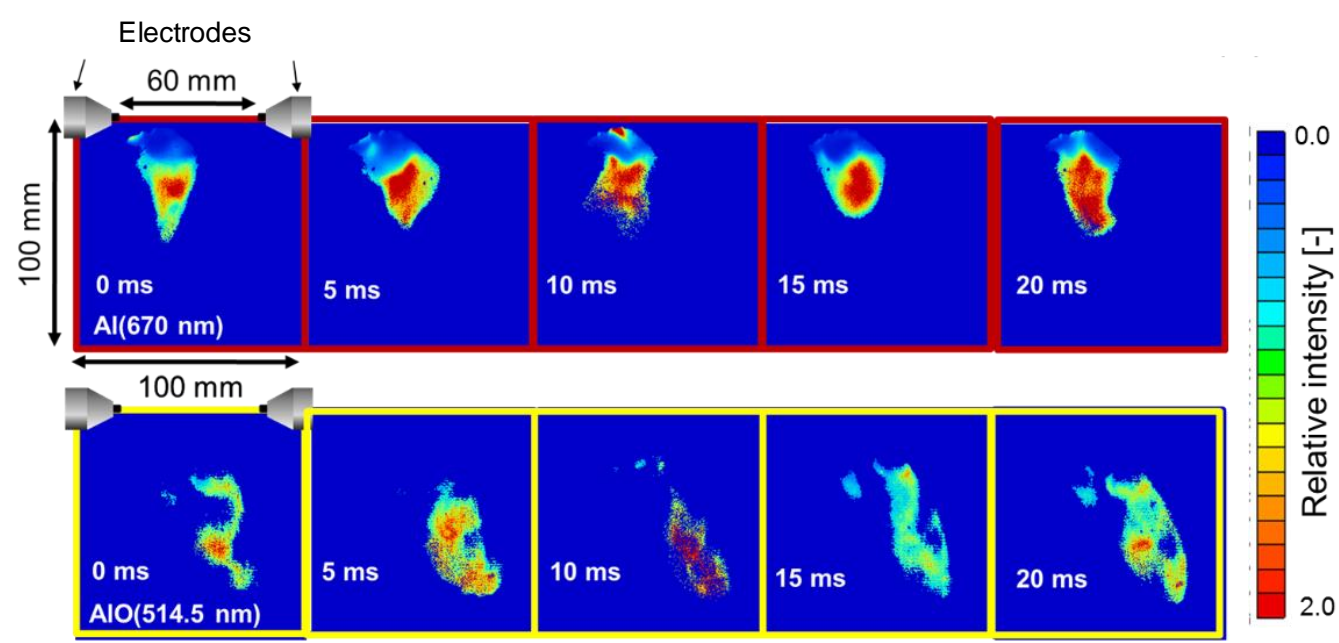

Fig. 9 Two-dimensional distributions of relative intensities of $\mathrm{Al} / \mathrm{Ar}$ and $\mathrm{AlO} / \mathrm{Ar}$.
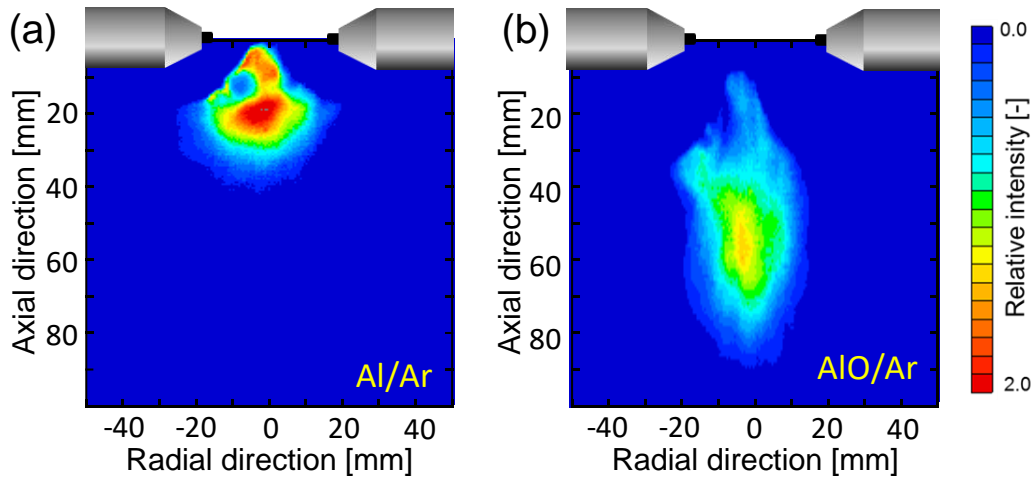

Fig. 10 Two-dimensional distributions of time-averaged relative intensities for $\mathrm{Al} / \mathrm{Ar}$ and $\mathrm{AlO} / \mathrm{Ar}$. 
(a)

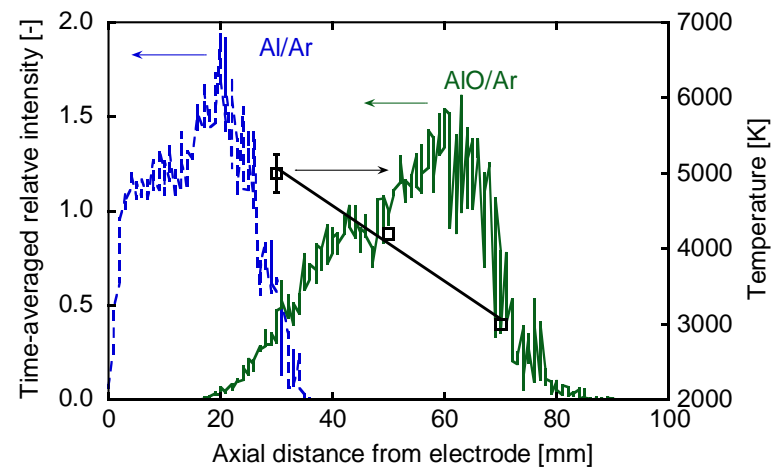

(b)

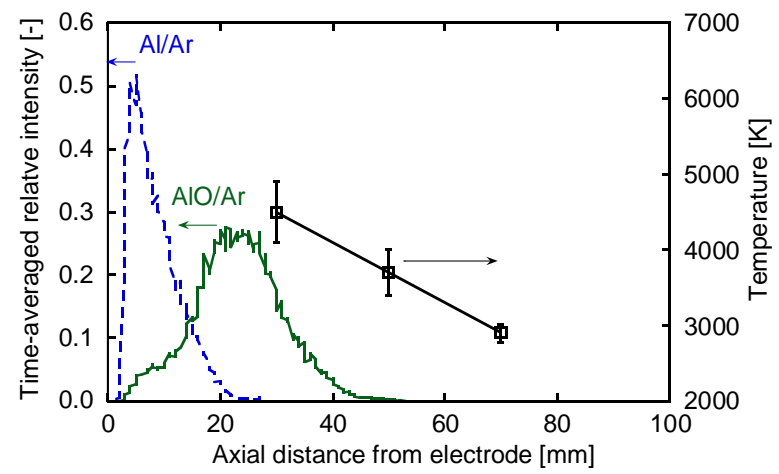

Fig. 11 Axial distributions of relative intensities of $\mathrm{Al} / \mathrm{Ar}$ and $\mathrm{AlO} / \mathrm{Ar}$ at oxygen concentration of $18 \%$ (b) and that of $29 \%$ (b). Axial temperature profiles are also plotted. (a)

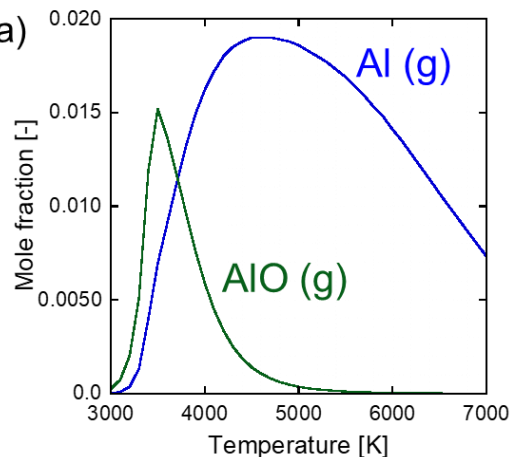

(b)

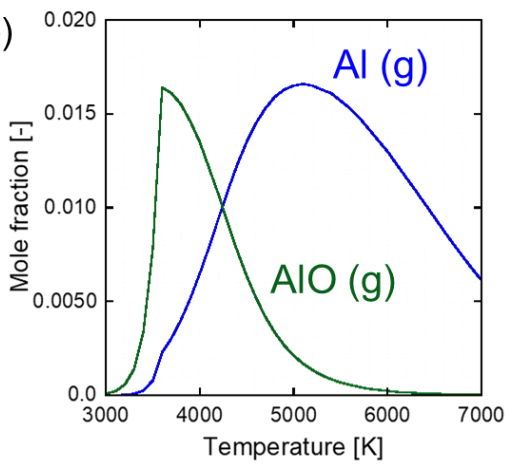

Fig. 12 Gas phase composition of aluminum vapor and aluminum oxide with different oxygen concentration of $18 \%$ (a) and $29 \%$ (b).

\section{Conclusion}

The dynamic behavior of metal oxide and metal vapor in the multiphase AC arc was successfully visualized by the high-speed camera with appropriate band-pass filters. According to the optical emission spectroscopy, the transmission wavelengths of $670.0 \pm 0.5 \mathrm{~nm}$ and $514.5 \pm 0.5 \mathrm{~nm}$ were selected for $\mathrm{Al}$ and $\mathrm{AlO}$, respectively. Obtained results in Al-O system indicated that the $\mathrm{Al}$ vapor was oxidized. Then, nucleation of $\mathrm{AlO}$ occurred forming $\mathrm{Al}_{2} \mathrm{O}_{3}$ nanoparticles. These understanding on metal oxide nanoparticles in thermal plasma enables to expand the capability of thermal plasma for nanofabrication at high processing rate.

\section{References}

Cheng, Y., Shigeta, M., Choi, S., Watanabe, T., Formation mechanism of titanium boride nanoparticles by RF induction thermal plasma, Chemical Engineering Journal, Vol. 183, No. 15 (2012) pp. 483-491.

Heberlein, J., Murphy, A.B., Thermal plasma waste treatment, Journal of Physics D: Applied Physics, Vol. 41, No. 5 (2008) doi.org/10.1088/0022-3727/41/5/053001.

Homma, K., Kambara, M., Yoshida, T., High-throughput production of nanocomposite $\mathrm{SiO}_{\mathrm{x}}$ powders by plasma spay physical vapor deposition for negative electrode of lithium ion batteries, Science and Technology of Advanced Materials, Vol.15, No.2 (2014), doi:10.1088/1468-6996/15/2/025006.

Kodama, N., Tanaka, Y., Kita, K., Uesugi, Y., Ishijima, T., Watanabe, S., Nakamura, K., A method for large-scale synthesis of Al-doped $\mathrm{TiO}_{2}$ nanopowder using pulse-mudulated induction thermal plasmas with time-controlled feedstock feeding, Journal Physics D: Applied Physics, Vol.47, No.19 (2014), doi:10.1088/0022$3727 / 47 / 19 / 195304$.

Kodama, N., Tanaka, Y., Kita, K., Uesugi, Y., Ishijima, T., Sueyasu, S., Nakamura, K., Fundamental study of Ti feedstock evaporation and the precursor formation process in inductively coupled thermal plasmas during $\mathrm{TiO}_{2}$ 
nanopowder synthesis, Journal Physics D: Applied Physics, Vol.49, No.30 (2016), https://doi.org/10.1088/00223727/49/30/305501.

Okuma, T., Maruyama, H., Hashizume, T., Tanaka, M., Watanabe, T., Nagai, H., Koiwasaki, T., Effects of driving frequency on temperature in a multiphase AC arc, IEEE Transactions on Plasma Science, Vol.47, No.1 (2018) pp.32-38

Shigeta, M., Watanabe, T., Numerical analysis for co-condensation processes in silicide nanoparticle synthesis using induction thermal plasmas at atmospheric pressure conditions, Journal of Materials Research, Vol. 20, (2005) pp. 2801-2811.

Shigeta, M., Watanabe, T., Growth mechanism of silicon-based functional nanoparticles fabricated by inductively coupled thermal plasmas, Journal of Physics D: Applied Physics, Vol. 40, No.8 (2007a) pp. 2801-2811.

Shigeta, M., Watanabe, T., Multi-component co-condensation model of Ti-based boride/silicide nanoparticle growth in induction thermal plasmas, Thin Solid Films, Vol. 515, No.9 (2007b) pp. 4217-4227.

Shigeta, M., Murphy, A.B., Thermal plasmas for nanofabrication, Journal of Physics D: Applied Physics, Vol. 44, No. 14 (2011) doi.org/10.1088/0022-3727/44/17/174025.

Shigeta, M., Watanabe, T., Effect of precursor fraction on silicide nanopowder growth under thermal plasma conditions: A computational study, Powder Technology, Vol. 288 (2016) pp. 191-201.

Tanaka, M., Imatsuji, T., Hashizume, T., Watanabe, T., Nagai, H., Koiwasaki, T., Okuma, T., Investigation of temperature characteristics of multiphase AC arc by high-speed visualization, Journal of Fluid Science and Technology, Vol.12, No.3 (2017), https://doi.org/10.1299/jfst.2017jfst0024.

Watanabe, T., Itoh H., Ishii, Y., Preparation of ultrafine particles of silicon base intermetallic compound by arc plasma method, Thin Solid Films, Vol. 390, (2001) pp. 44-50.

Watanabe, T., Yatsuda K., Yao, Y., Yano, T., Matsuura, T., Innovative in-flight glass melting technology using thermal plasmas, Pure and Applied Chemistry, Vol. 82, No. 6 (2010) pp. 1337-1351. 